\title{
Internal and External Dispersal of Plants by Animals: An Aquatic Perspective on Alien Interference
}

\author{
Casper H. A. van Leeuwen* \\ Department of Aquatic Ecology, Netherlands Institute of Ecology (NIOO-KNAW), Wageningen, Netherlands
}

OPEN ACCESS

Edited by:

Janne Alahuhta,

University of Oulu, Finland

Reviewed by:

Carl R. Gosper,

Department of Parks and Wildlife,

Australia

Fei-Hai Yu,

Taizhou University, China

*Correspondence:

Casper H. A. van Leeuwen

c.vanleeuwen@nioo.knaw.nl

Specialty section:

This article was submitted to

Functional Plant Ecology,

a section of the journal

Frontiers in Plant Science

Received: 10 October 2017

Accepted: 29 January 2018

Published: 13 February 2018

Citation:

van Leeuwen CHA (2018) Internal and

External Dispersal of Plants by

Animals: An Aquatic Perspective on

Alien Interference.

Front. Plant Sci. 9:153.

doi: 10.3389/fp/s.2018.00153
Many alien plants use animal vectors for dispersal of their diaspores (zoochory). If alien plants interact with native disperser animals, this can interfere with animal-mediated dispersal of native diaspores. Interference by alien species is known for frugivorous animals dispersing fruits of terrestrial plants by ingestion, transport and egestion (endozoochory). However, less attention has been paid to possible interference of alien plants with dispersal of diaspores via external attachment (ectozoochory, epizoochory or exozoochory), interference in aquatic ecosystems, or positive effects of alien plants on dispersal of native plants. This literature study addresses the following hypotheses: (1) alien plants may interfere with both internal and external animal-mediated dispersal of native diaspores; (2) interference also occurs in aquatic ecosystems; (3) interference of alien plants can have both negative and positive effects on native plants. The studied literature revealed that alien species can comprise large proportions of both internally and externally transported diaspores. Because animals have limited space for ingested and adhering diaspores, alien species affect both internal and external transport of native diaspores. Alien plant species also form large proportions of all dispersed diaspores in aquatic systems and interfere with dispersal of native aquatic plants. Alien interference can be either negative (e.g., through competition with native plants) or positive (e.g., increased abundance of native dispersers, changed disperser behavior or attracting additional disperser species). I propose many future research directions, because understanding whether alien plant species disrupt or facilitate animal-mediated dispersal of native plants is crucial for targeted conservation of invaded (aquatic) plant communities.

Keywords: ectozoochory, endozoochory, exotic, frugivore, invasive, mutualism, non-native, seed

\section{INTRODUCTION}

Dispersal of plant diaspores by animals (zoochory) is a globally important mechanism regulating species diversity of plant communities. Key disperser species include birds, mammals, and fishof which many forage on plant diaspores, transport them internally during digestion, and defecate viable diaspores in new locations (endozoochory, Horn et al., 2011; Van Leeuwen et al., 2012; Albert et al., 2015; Corlett, 2017). Plant diaspores are also transported externally on animals by adhering to their feathers, fur or feet (referred to as ectozoochory, epizoochory or exozoochory; Sorensen, 1986; Will et al., 2007; Coughlan et al., 2017). Zoochory can provide long-distance transport over several hundreds of kilometers (Viana et al., 2016), but is also important at local scales (Kleyheeg et al., 2017). Morphological adaptations of diaspores for zoochory are therefore abundant in both 
temperate (35-60\% of all terrestrial plant species) and tropical (75-90\% of all woody plant species) regions (Willson et al., 1990; Jordano, 2000; Herrera, 2003).

Humans also transport many plant diaspores across the world, which frequently introduces alien species into networks of native plants and animals (Ricciardi, 2007; Hulme, 2015). Alien species can comprise large proportions of all species in ecosystems (Pyšek, 1998). Arrival of alien species in native communities can have numerous ecological and evolutionary consequences, notably if alien species naturalize and start new interactions with native species (Richardson et al., 2000a; Vilà et al., 2011; Dickie et al., 2017). These new species interactions between alien and native species can alter the interactions that were previously present among only native species (Traveset et al., 2015). For example, insects pollinating native flowers can start to prefer flowers of alien plants (Gibson et al., 2013), or birds previously foraging on native seeds can start ingesting and dispersing mainly alien seeds (Heleno et al., 2013). Recent reviews have convincingly shown this potential of alien species to interfere with native species interactions (Traveset and Richardson, 2006, 2011, 2014), and the implications of this for conservation (Buckley et al., 2006).

Most studies to date, however, investigated this phenomenon for internally transported terrestrial plant seeds and fruits. The aim of this literature study is to explore the potential of alien species to interfere with external transport of plant diaspores, to examine potential interference specifically in aquatic ecosystems, and to evaluate whether alien species commonly have negative or positive effects on native plant species. I therefore address the following three hypotheses: (1) alien plant species may interfere with both internal and external animal-mediated dispersal of native diaspores; (2) interference by alien plants also commonly occurs in aquatic ecosystems; and (3) interference by alien plants can have both negative and positive effects on native plants. I focus on zoochory of plant diaspores (mostly fruits and seeds, here respectively considered the fleshy parts and hard structures of reproductive units) by vertebrate animals. "Alien species" is used as the terminology throughout this study to refer to all non-native, invasive, introduced or exotic species that established a self-sustaining reproductive population outside their native geographic area (naturalized sensu Richardson et al., 2000b).

\section{EFFECTS OF ALIEN PLANTS ON ENDO- AND ECTOZOOCHORY}

Interference of alien diaspores is best known for endozoochory. Common interference involves disperser animals ingesting alien plant diaspores instead of native diaspores (Traveset and Richardson, 2006, 2011, 2014). The level of interference by alien species therefore relies strongly on their relative attractiveness to foraging disperser species. Most key disperser species for endozoochory-such as frugivorous birds (Jordano, 2000), waterbirds (Reynolds et al., 2015; Green, 2016), large mammals (Albert et al., 2015), and fish (Horn et al., 2011) —forage highly selectively on the richest food sources (Pyke et al., 1977). Diaspore ingestion therefore strongly relies on diaspore traits like attractive coloring, high nutrient content, small or large size, high sugar content, or long fruiting periods (e.g., Levey and Del Rio, 2001; Gosper et al., 2005; Westcott and Fletcher, 2011). Hence, especially attractive alien species may become incorporated into the diets of native animals, cause interference, and have great potential to disrupt endozoochory as a dispersal mechanism.

Interference with ectozoochory may work analogously, but has been little investigated. Ectozoochory by vertebrates is most common for diaspores that use hooks, mud or mucus to attach to fur, hooves, feathers or feet (Sorensen, 1986; Van Leeuwen and Van Der Velde, 2012; Schulze et al., 2014; Reynolds and Cumming, 2016; Coughlan et al., 2017). Because space on animals for diaspore attachment is limited, animals that already carry many diaspores will have less space available for attachment of native diaspores. This implies that also for externally dispersed diaspores, alien plant species may interfere with dispersal of native plant species. However, to my knowledge, no studies have specifically addressed this idea.

The impact of interference likely differs between native diaspores relying on either endo- or ectozoochory, which can be better understood by looking at the evolutionary histories of both dispersal mechanisms. While endozoochory is mostly a mutualistic interaction that benefits both the plant and animal, ectozoochory is commonly only beneficial for plants and has little or no direct effects on animals. Diaspore morphology is important for dispersal in the case of both dispersal mechanisms-for instance for survival during transport-but only for endozoochory the uptake phase in the dispersal process involves active diaspore selection by foraging animals. For endozoochory, examples of disperser animals preferring alien diaspores over native diaspores are common: Canada geese (Branta canadensis) feed selectively on Eurasian grasses in Canada (Best and Arcese, 2009), various native South African bird species disproportionately feed on an alien shrub with very abundant and nutritious fruits (Mokotjomela et al., 2013b,c), and Black-tailed jackrabbits (Lepus californicus) and mule deers (Odocoileus hemionus) remove fruits of an alien succulent faster than those of a native species in the same genus (Vilà and D'Antonio, 1998). This implies that active selection by disperser animals plays an important role in alien interference, at least in the case of endozoochory. For ectozoochory, active diaspore selection is lacking. This puts forward the idea that alien species may have a stronger potential to interfere with endozoochory than ectozoochory, which should be further studied.

This section indicated that alien interference with ectozoochory is plausible, but may be less disruptive than in cases of endozoochory. It mostly indicated, however, that interference with ectozoochory is a hardly studied phenomenon that warrants investigation. Key directions for future research therefore include (1) studying interference of alien plants with ectozoochory by itself, and simultaneously with interference of endozoochory in single model systems; and (2) comparing the relative effectiveness of alien and native diaspores for endo- and ectozoochory in choice and attachment experiments (see e.g., 
Greenberg et al., 2001; Gosper et al., 2006; Mokotjomela et al., 2013a,b). We can expect highly attractive alien diaspores, those with high similarity to native diaspores (Gosper and VivianSmith, 2009), or with disproportionally strong attachment capabilities (Will et al., 2007; Collas et al., 2014) to cause greater interference with zoochory. (3) Lastly, alien impact can strongly change over time since invasion (e.g., Strayer et al., 2017), which could be used to detect evolutionary responses in diaspore traits of native species. This would require comparative studies on systems that have been invaded at different moments in the past, or could be analyzed by using historic data.

\section{EFFECTS OF ALIEN PLANT SPECIES ON ZOOCHORY IN AQUATIC SYSTEMS}

The existence of several recent reviews on alien interference with endozoochory of terrestrial plant species (Traveset and Richardson, 2006, 2011, 2014) —and the lack thereof for aquatic ecology-suggests that interference is mostly a concern for the conservation of terrestrial ecosystems. This section explores whether interference has also been documented in aquatic habitats, because if so, it could have analogous consequences for aquatic ecosystems and provide interesting direction for future (aquatic) research.

To compare study effort on alien interference between habitats and among disperser animals, I performed a standardized search for publications reporting the presence of alien and native aquatic diaspores in single samples of feces or attached to native vertebrate animals in ISI Web of Science. On the 11th of January 2018 I entered the following search string: TS = (alien OR exotic OR non-native OR invas* OR introduce*) AND TS $=$ (seed OR diaspore* OR fruit OR nut); combined with either TS $=$ (frugivor* $\mathrm{OR}$ endozoochor*) or with $\mathrm{TS}=$ (ectozoochor* OR epizoochor* OR exozoochor*). This resulted in respectively 376 and 36 studies that addressed dispersal of alien plants for endo- and ectozoochory. Addition of the term $\mathrm{TS}=$ (aquatic OR wetland OR freshwater OR riparian) reduced the publication counts to respectively 16 and 6 , indicating that a low percentage of all studies involved aquatic habitats.

Examples of interference with endozoochory notably included cases with terrestrial birds, such as silvereye Zosterops lateralis, Japanese white-eye Zosterops japonicas, southern cassowary Casuarius casuarius and emus Dromaius novaehollandia (Stanley and Lill, 2002; Bradford et al., 2008; Kawakami et al., 2009; Calvino-Cancela, 2011) or mammals such as deer, boar and cattle (Bartuszevige and Endress, 2008; Vignolio and Fernández, 2010; Dovrat et al., 2012). I found few studies on potential interference for other major disperser animals such as bats, and no studies on fish or reptiles. Examples of externally dispersed alien diaspores (and although not explicitly mentioned thus potentially interfering with native diaspore dispersal) mostly studied mammals such as bison Bison bison, wild boar Sus scrofa and cattle (Constible et al., 2005; Dovrat et al., 2012; Chuong et al., 2016). For ectozoochory, there is a need for more studies on other taxa than mammals.

A more detailed search to specifically examine interference in aquatic ecosystems in Web of Science and Google Scholar, and a cross-reference search on recent reviews (Reynolds et al., 2015; Green, 2016), resulted in a total of 8 publications on endozoochory (Table 1) and 5 on ectozoochory (Table 2) reporting data interpretable for interference by alien species. The need for this more extensive search, however, revealed a problem. Many studies on zoochory-and therefore potentially reporting interference-do not report the native or alien status of dispersed diaspores (e.g., Viviansmith and Stiles, 1994). Without specific knowledge on the exact study systems and dispersed taxa, potential interference of alien plants with zoochory is easily overlooked by readers that lack systemspecific knowledge - and impossible to detect in searches on alien species. I therefore recommend future studies on zoochory to report the alien/native status of dispersed taxa more explicitly, as this will greatly advance our understanding of the scale of potential interference across ecosystems and taxa.

All aquatic studies jointly reported 34 cases of potential interference by alien plants with dispersal of native diasporesby native disperser animals-and in aquatic ecosystems (Tables 1, 2). The percentages of alien species in feces or attached to single disperser animals ranged from 0 to $100 \%$ of all diaspores being alien, which was the case for both endozoochory and ectozoochory (Tables 1, 2). The mean percentage of alien species was $38 \%$ for endozoochory ( $n=1142$ fecal samples) and $55 \%$ for ectozoochory ( $n=620$ investigated animals). In 5 of the 19 reports on endozoochory and 8 of the 15 reports of ectozoochory more alien than native diaspores were dispersed. However, these numbers should be interpreted with caution because variation among geographic locations and studied species was large, and studies reporting only dispersal of native diaspores were not included.

The presented cases illustrate that patterns of alien interference thus far primarily described in terrestrial ecosystems may also apply to aquatic ecosystems. Future research should focus on under-examined disperser animals like fish, bats and reptiles (Horn et al., 2011; Jordaan et al., 2011; Platt et al., 2013). Studying broader taxonomic ranges of both diaspores and disperser animals can identify which native communities are most susceptible to interference by alien species, test for differences between interference in species rich and species poor communities, analyze latitudinal trends, or detect new suitable model systems in which interference with endo- and ectozoochory can be studied simultaneously. Furthermore, disperser diets and adhering diaspores could be compared between situations from before and after invasions in the same system if more data are available (Gosper et al., 2006). Levels of alien interference could be contrasted between endo- and ectozoochory and among different disperser species in the same community; for instance by supplementing field or laboratory setups simultaneously with externally and internally dispersing alien diaspores. 


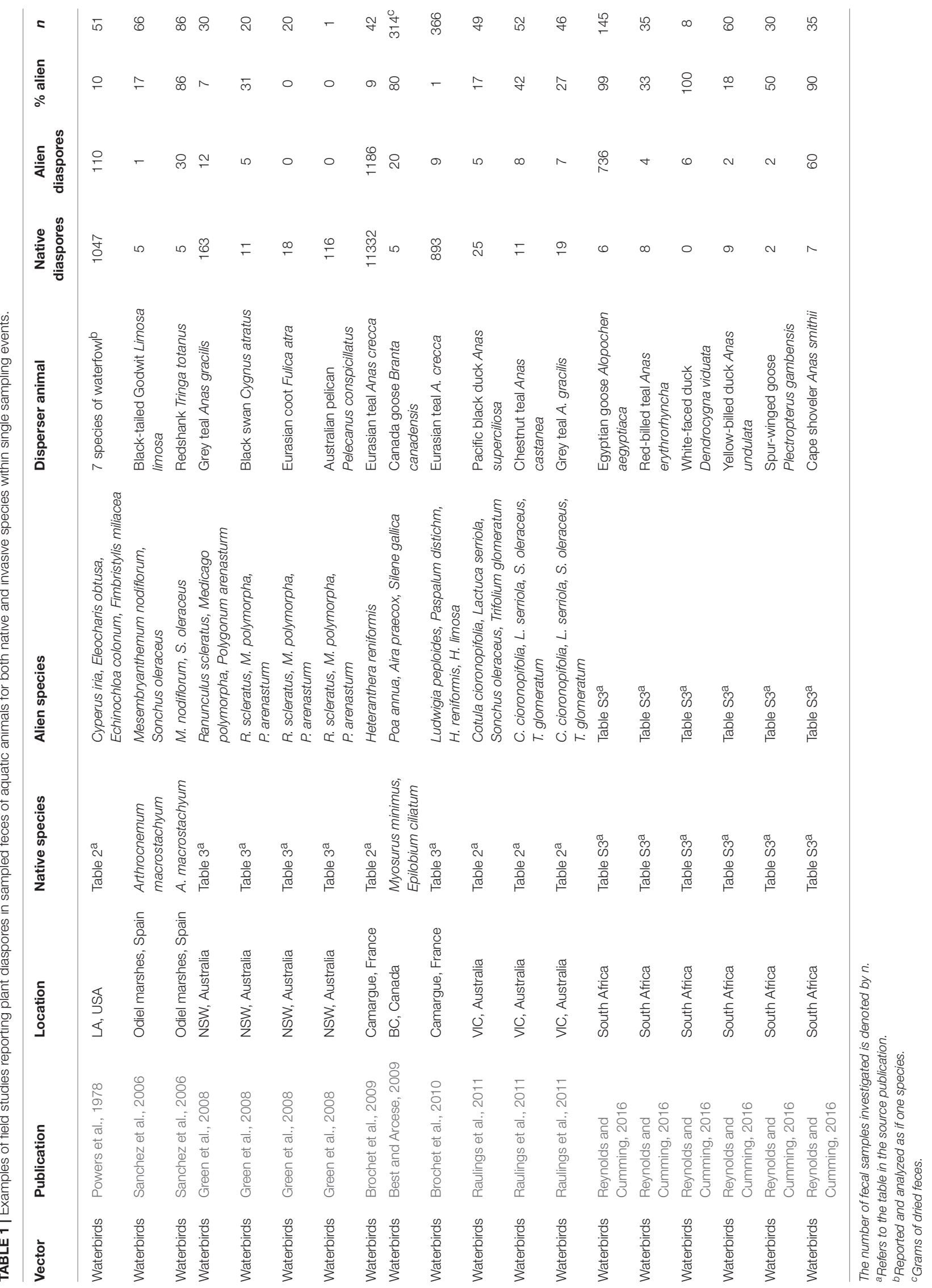




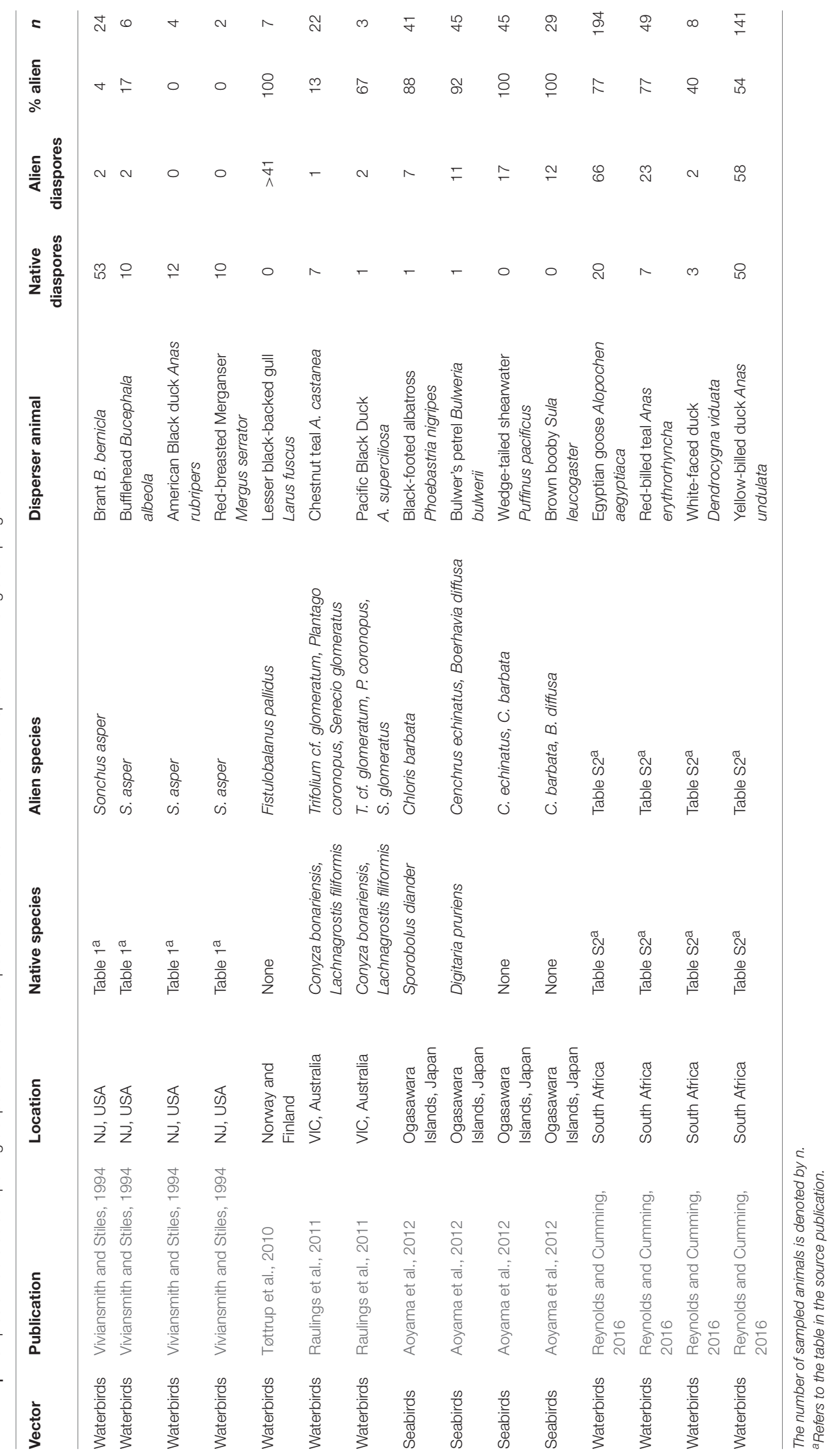




\section{POSITIVE AND NEGATIVE EFFECTS OF ALIEN PLANTS ON ZOOCHORY OF NATIVE PLANTS}

The fact that alien plants can interfere with zoochory of native plants in terrestrial and aquatic ecosystems raises questions about the magnitude and the directions of these effects. Especially directions are crucial to understand in the light of possible control or eradication of alien species for conservation. This section explores possible negative and positive effects of alien species on endo- and ectozoochory of native species.

Introductions of alien species are commonly associated with loss of native species and deteriorating ecosystems, because alien species are thought to directly outcompete native species or indirectly affect abiotic conditions (Morales and Traveset, 2009; Havel et al., 2015; Gilioli et al., 2017). However, alien species that successfully integrate into resident communities can also stabilize networks by increasing network nestedness (Bascompte et al., 2003; Traveset et al., 2013), boost productivity by increasing overall species richness (Cardinale et al., 2006) or provide new ecosystem services to native species (Gleditsch, 2017). Alien species can benefit disturbed communities (Lugo, 2004) or compensate for the loss of native species (Kawakami et al., 2009). I here discuss the possibility that alien species stimulate zoochory of native species by exploring two possible mechanisms: alien species may affect the abundances or behavior of native disperser animals, or may facilitate the arrival of new alien disperser species.

The first possible mechanism assumes that establishment of alien plants can increase the local densities of native disperser animals already present in the community. The attractiveness of an individual plant for disperser animals relies partly on its surrounding plant species (Carlo, 2005), which is a well-established phenomenon in pollination ecology (e.g., Bruckman and Campbell, 2016). Because most animals actively track fluctuations in resources across the landscape (Saracco et al., 2004; Cameron and Bayne, 2012), productive alien plant species at high densities can increase abundances of disperser species or alter their movement behavior. Reports of this scenario are still rare, but an elegant example involves two invasive Lonicera species that attract native birds to their fruits, which increases removal of nearby native fruits by onethird (Gleditsch and Carlo, 2011). Hence, productive alien plants can increase densities of local native dispersers that can transport native diaspores either internally or externally. We can expect alien species that provide attractive new resources to native dispersers - and are therefore often dispersed via endozoochory-to have a greater potential to influence abundances and behavior of native disperser animals than alien plants primarily dispersed by passive attachment to animals.

The second possible mechanism is through the attraction of new alien disperser animal species. Alien plants can facilitate establishment of alien animal species relying on newly provided resources such as food, refugia against predators, or nesting substrate (Chiba, 2010; Schlossberg and King, 2010; Schlaepfer et al., 2011; Nelson et al., 2017). Hence, new disperser animals may be attracted by alien plants, which could also benefit either endo- or ectozoochory of native plant species. However, in case of endozoochory, alien animals often forage primarily on alien fruits (Chimera and Drake, 2010; Garcia et al., 2014; Pejchar, 2015; Schor et al., 2015), and their movement after ingestion can deviate from that of native dispersers. If alien disperser animals compete with native disperser animals, the potential for effective and successful endozoochory to suitable habitat may actually decrease. For ectozoochory, addition of new disperser species with differing behavior from native dispersers may vary from facilitation of range expansions to transport of diaspores to unsuitable habitats because of unfitting movement behavior. The overall effect of new alien dispersers on native plants will therefore largely vary among species networks and dispersal mechanisms.

The above examples suggest that alien plant species can-in some systems-actually positively affect endo- and ectozoochory of native species via trophic interactions (e.g., Gleditsch and Carlo, 2011). However, they also indicate that this is still a little explored research direction. Fruitful directions for future studies are therefore to (1) experimentally attract disperser animals with artificial diaspores to mimic attraction by alien species (Galetti et al., 2003) in the field or in laboratory setups, and monitor the effects on zoochory of native plants; (2) use large, longterm datasets on species interactions that are currently becoming available (Bello et al., 2017) to compare species interactions and networks between before and after invasions; (3) further explore the effects of timing of fruit set on species interactions. Competition of aliens with natives plants is strongly related to the timing of fruit sets (Buckley et al., 2006) and uncoupled fruiting seasons may lower possible competition for dispersers, while longer fruiting seasons may have positive effects on disperser species. These possible scenarios could be contrasted using theoretical modeling or field data. Finally, (4) future studies can extract directions from the strong analogies with pollination ecology (e.g., Richardson et al., 2000a; Traveset and Richardson, 2006; Bjerknes et al., 2007; Seifan et al., 2014; Bruckman and Campbell, 2016).

\section{INTEGRATIVE CONCLUSIONS}

This study explored interference of alien plant species with zoochory of native plants, and concludes that (1) although the phenomenon has been primarily studied for endozoochory by frugivorous birds and mammals in terrestrial ecosystems, alien species may also interfere with ectozoochory and this warrants further studying; (2) interference of alien species with zoochory can similarly be found in aquatic ecosystems; (3) alien plant species can also provide resources such as food or nesting habitat to animals, which can increase densities of native disperser animals or attract new disperser animal species. Through these mechanisms alien plants can also positively affect dispersal of native plants, which warrants 
further studying. This study illustrates that the impacts of alien plant species on native plant species, whether positive or negative, can vary among native plant species relying on different dispersal mechanisms. Understanding species interactions is crucial for effective conservation, especially in invaded ecosystems.

\section{AUTHOR CONTRIBUTIONS}

CvL designed the study, collected and analyzed the data, and wrote the manuscript.

\section{REFERENCES}

Albert, A., Auffret, A. G., Cosyns, E., Cousins, S. A. O., D’hondt, B., Eichberg, C., et al. (2015). Seed dispersal by ungulates as an ecological filter: a trait-based meta-analysis. Oikos 124, 1109-1120. doi: 10.1111/oik.02512

Aoyama, Y., Kawakami, K., and Chiba, S. (2012). Seabirds as adhesive seed dispersers of alien and native plants in the oceanic Ogasawara Islands, Japan. Biodivers. Conserv. 21, 2787-2801. doi: 10.1007/s10531-012-0336-9

Bartuszevige, A. M., and Endress, B. A. (2008). Do ungulates facilitate native and exotic plant spread? J. Arid Environ. 72, 904-913. doi: 10.1016/j.jaridenv.2007.11.007

Bascompte, J., Jordano, P., Melián, C. J., and Olesen, J. M. (2003). The nested assembly of plant-animal mutualistic networks. Proc. Natl. Acad. Sci. U.S.A. 100, 9383-9387. doi: 10.1073/pnas.1633576100

Bello, C., Galetti, M., Montan, D., Pizo, M. A., Mariguela, T. C., Culot, L., et al. (2017). Atlantic frugivory: a plant-frugivore interaction data set for the Atlantic Forest. Ecology 98, 1729-1729. doi: 10.1002/ecy.1818

Best, R. J., and Arcese, P. (2009). Exotic herbivores directly facilitate the exotic grasses they graze: mechanisms for an unexpected positive feedback between invaders. Oecologia 159, 139-150. doi: 10.1007/s00442-008-1172-1

Bjerknes, A.-L., Totland, Ø., Hegland, S. J., and Nielsen, A. (2007). Do alien plant invasions really affect pollination success in native plant species? Biol. Conserv. 138, 1-12. doi: 10.1016/j.biocon.2007.04.015

Bradford, M. G., Dennis, A. J., and Westcott, D. A. (2008). Diet and dietary preferences of the southern cassowary (Casuarius casuarius) in North Queensland, Australia. Biotropica 40, 338-343. doi: 10.1111/j.1744-7429.2007.00372.x

Brochet, A. L., Guillemain, M., Fritz, H., Gauthier-Clerc, M., and Green, A. J. (2009). The role of migratory ducks in the long-distance dispersal of native plants and the spread of exotic plants in Europe. Ecography 32, 919-928. doi: 10.1111/j.1600-0587.2009.05757.x

Brochet, A. L., Guillemain, M., Fritz, H., Gauthier-Clerc, M., and Green, A. J. (2010). Plant dispersal by teal (Anas crecca) in the Camargue: duck guts are more important than their feet. Freshw. Biol. 55, 1262-1273. doi: 10.1111/j.1365-2427.2009.02350.x

Bruckman, D., and Campbell, D. R. (2016). Pollination of a native plant changes with distance and density of invasive plants in a simulated biological invasion. Am. J. Bot. 103, 1458-1465. doi: 10.3732/ajb.1600153

Buckley, Y. M., Anderson, S., Catterall, C. P., Corlett, R. T., Engel, T., Gosper, C. R., et al. (2006). Management of plant invasions mediated by frugivore interactions. J. Appl. Ecol. 43, 848-857. doi: 10.1111/j.1365-2664.2006.01210.x

Calvino-Cancela, M. (2011). Seed dispersal of alien and native plants by vertebrate herbivores. Biol. Invasions 13, 895-904. doi: 10.1007/s10530-010-9877-6

Cameron, E. K., and Bayne, E. M. (2012). Invasion by a non-native ecosystem engineer alters distribution of a native predator. Divers. Distrib. 18, 1190-1198. doi: 10.1111/j.1472-4642.2012.00912.x

Cardinale, B. J., Srivastava, D. S., Duffy, J. E., Wright, J. P., Downing, A. L., Sankaran, M., et al. (2006). Effects of biodiversity on the functioning of trophic groups and ecosystems. Nature 443, 989-992. doi: 10.1038/nature05202

Carlo, T. A. (2005). Interspecific neighbors change seed dispersal pattern of an avian-dispersed plant. Ecology 86, 2440-2449. doi: 10.1890/04-1479

\section{FUNDING}

This study was supported by Marie S-Curie Actions-H2020 grant 750240 of the EU to CvL.

\section{ACKNOWLEDGMENTS}

I thank Antonella Petruzzella, Carl R. Gosper, and Fei-Hai Yu for helpful comments on an earlier version of this manuscript. This is publication number 6472 from the Netherlands Institute of Ecology.

Chiba, S. (2010). Invasive non-native species' provision of refugia for endangered native species. Conserv. Biol. 24, 1141-1147. doi: 10.1111/j.1523-1739.2010.01457.x

Chimera, C. G., and Drake, D. R. (2010). Patterns of seed dispersal and dispersal failure in a Hawaiian dry forest having only introduced birds. Biotropica 42, 493-502. doi: 10.1111/j.1744-7429.2009.00610.x

Chuong, J., Huxley, J., Spotswood, E. N., Nichols, L., Mariotte, P., and Suding, K. N. (2016). Cattle as dispersal vectors of invasive and introduced plants in a California annual grassland. Rang. Ecol. Man. 69, 52-58. doi: 10.1016/j.rama.2015.10.009

Collas, F. P. L., Koopman, K. R., Hendriks, A. J., Van Der Velde, G., Verbrugge, L. N. H., and Leuven, R. S. E. W. (2014). Effects of desiccation on native and non-native molluscs in rivers. Freshw. Biol. 59, 41-55. doi: 10.1111/fwb.12244

Constible, J. M., Sweitzer, R. A., Vuren, D. H. V., Schuyler, P. T., and Knapp, D. A. (2005). Dispersal of non-native plants by introduced bison in an island ecosystem. Biol. Invasions 7, 699-709. doi: 10.1007/s10530-004-5859-x

Corlett, R. T. (2017). Frugivory and seed dispersal by vertebrates in tropical and subtropical Asia: an update. Glob. Ecol. Con. 11, 1-22. doi: 10.1016/j.gecco.2017.04.007

Coughlan, N. E., Kelly, T. C., Davenport, J., and Jansen, M.A. K. (2017). Up, up and away: bird-mediated ectozoochorous dispersal between aquatic environments. Freshw. Biol. 62:631. doi: 10.1111/fwb.12894

Dickie, I. A., Bufford, J. L., Cobb, R. C., Desprez-Loustau, M. L., Grelet, G., Hulme, P. E., et al. (2017). The emerging science of linked plant-fungal invasions. New Phytol. 215, 1314-1332. doi: 10.1111/nph.14657

Dovrat, G., Perevolotsky, A., and Ne'eman, G. (2012). Wild boars as seed dispersal agents of exotic plants from agricultural lands to conservation areas. J. Arid Environ. 78, 49-54. doi: 10.1016/j.jaridenv.2011.11.011

Galetti, M., Alves-Costa, C. P., and Cazetta, E. (2003). Effects of forest fragmentation, anthropogenic edges and fruit colour on the consumption of ornithocoric fruits. Biol. Conserv. 111, 269-273. doi: 10.1016/S0006-3207(02)00299-9

Garcia, D., Martinez, D., Stouffer, D. B., and Tylianakis, J. M. (2014). Exotic birds increase generalization and compensate for native bird decline in plant-frugivore assemblages. J. Anim. Ecol. 83, 1441-1450. doi: 10.1111/1365-2656.12237

Gibson, M. R., Pauw, A., and Richardson, D. M. (2013). Decreased insect visitation to a native species caused by an invasive tree in the Cape floristic region. Biol. Conserv. 157, 196-203. doi: 10.1016/j.biocon.2012.07.011

Gilioli, G., Schrader, G., Carlsson, N., Van Donk, E., Van Leeuwen, C. H., Martín, P. R., et al. (2017). Environmental risk assessment for invasive alien species: a case study of apple snails affecting ecosystem services in Europe. Env. Impact. Ass. Rev. 65, 1-11. doi: 10.1016/j.eiar.2017.03.008

Gleditsch, J. M. (2017). "The role of invasive plant species in urban avian conservation," in Ecology and Conservation of Birds in Urban Environments, eds E. Murgui and M. Hedblom (Cham: Springer International Publishing), 413-424.

Gleditsch, J. M., and Carlo, T. A. (2011). Fruit quantity of invasive shrubs predicts the abundance of common native avian frugivores in central Pennsylvania. Divers. Distrib. 17, 244-253. doi: 10.1111/j.1472-4642.2010. 00733.x 
Gosper, C. R., Stansbury, C. D., and Vivian-Smith, G. (2005). Seed dispersal of fleshy-fruited invasive plants by birds: contributing factors and management options. Divers. Distrib. 11, 549-558. doi: 10.1111/j.1366-9516.2005.00195.x

Gosper, C. R., and Vivian-Smith, G. (2009). Approaches to selecting native plant replacements for fleshy-fruited invasive species. Restor. Ecol. 17, 196-204. doi: 10.1111/j.1526-100X.2008.00374.x

Gosper, C. R., Whelan, R. J., and French, K. (2006). The effect of invasive plant management on the rate of removal of vertebrate-dispersed fruits. Plant Ecol. 184, 351-363. doi: 10.1007/s11258-005-9078-z

Green, A. J. (2016). The importance of waterbirds as an overlooked pathway of invasion for alien species. Divers. Distrib. 22, 239-247. doi: 10.1111/ddi.12392

Green, A. J., Jenkins, K. M., Bell, D., Morris, P. J., and Kingsford, R. T. (2008), The potential role of waterbirds in dispersing invertebrates and plants in arid Australia. Freshw. Biol. 53, 380-392. doi: 10.1111/j.1365-2427.2007.01901.x

Greenberg, C. H., Smith, L. M., and Levey, D. J. (2001). Fruit fate, seed germination and growth of an invasive vine - an experimental test of 'sit and wait' strategy. Biol. Invasions 3, 363-372. doi: 10.1023/A:1015857721486

Havel, J., Kovalenko, K., Thomaz, S., Amalfitano, S., and Kats, L. (2015). Aquatic invasive species: challenges for the future. Hydrobiologia 750, 147-170. doi: 10.1007/s10750-014-2166-0

Heleno, R. H., Ramos, J. A., and Memmott, J. (2013). Integration of exotic seeds into an Azorean seed dispersal network. Biol. Invasions 15, 1143-1154. doi: 10.1007/s10530-012-0357-Z

Herrera, C. M. (2003). "Seed dispersal by vertebrates," in Plant-Animal Interactions: An Evolutionary Approach, eds C. M. Herrera and O. Pellmyr. (Oxford: Blackwell), 185-208.

Horn, M. H., Correa, S. B., Parolin, P., Pollux, B. J. A., Anderson, J. T., Lucas, C., et al. (2011). Seed dispersal by fishes in tropical and temperate fresh waters: the growing evidence. Acta Oecol. 37, 561-577. doi: 10.1016/j.actao.2011.06.004

Hulme, P. E. (2015). Invasion pathways at a crossroad: policy and research challenges for managing alien species introductions. J. Appl. Ecol. 52, 1418-1424. doi: 10.1111/1365-2664.12470

Jordaan, L. A., Johnson, S. D., and Downs, C. T. (2011). Wahlberg's epauletted fruit bat (Epomophorus wahlbergi) as a potential dispersal agent for fleshy-fruited invasive alien plants: effects of handling behaviour on seed germination. Biol. Invasions 14, 959-968. doi: 10.1007/s10530-011-0131-7

Jordano, P. (2000). "Fruits and frugivory," in Seeds: The Ecology Of Regeneration in Plant Communities, 2nd Edn., ed M. Fenner. (Wallingford: Cabi publishers), $125-166$.

Kawakami, K., Mizusawa, L., and Higuchi, H. (2009). Re-established mutualism in a seed-dispersal system consisting of native and introduced birds and plants on the Bonin Islands, Japan. Ecol. Res. 24, 741-748. doi: $10.1007 / \mathrm{s} 11284-008-0543-8$

Kleyheeg, E., Treep, J., De Jager, M., Nolet, B. A., and Soons, M. B. (2017). Seed dispersal distributions resulting from landscape-dependent daily movement behaviour of a key vector species, Anas platyrhynchos. J. Ecol. 105, 1279-1289. doi: $10.1111 / 1365-2745.12738$

Levey, D. J., and Del Rio, C. M. (2001). It takes guts (and more) to eat fruit: lessons from avian nutritional ecology. Auk 118, 819-831. doi: 10.1642/00048038(2001)118[0819:ITGAMT]2.0.CO;2

Lugo, A. E. (2004). The outcome of alien tree invasions in Puerto Rico. Fron. Ecol. Env. 2, 265-273. doi: 10.1890/1540-9295(2004)002[0265:TOOATI]2.0.CO;2

Mokotjomela, T. M., Musil, C. F., and Esler, K. J. (2013a). Do frugivorous birds concentrate their foraging activities on those alien plants with the most abundant and nutritious fruits in the South African Mediterranean-climate region? Plant Ecol. 214, 49-59. doi: 10.1007/s11258-012-0145-y

Mokotjomela, T. M., Musil, C. F., and Esler, K. J. (2013b). Frugivorous birds visit fruits of emerging alien shrub species more frequently than those of native shrub species in the South African Mediterranean climate region. S. Afr. J. Bot. 86, 73-78. doi: 10.1016/j.sajb.2013.02.004

Mokotjomela, T. M., Musil, C. F., and Esler, K. J. (2013c). Potential seed dispersal distances of native and non-native fleshy fruiting shrubs in the South African Mediterranean climate region. Plant Ecol. 214, 1127-1137. doi: 10.1007/s11258-013-0237-3

Morales, C. L., and Traveset, A. (2009). A meta-analysis of impacts of alien vs. native plants on pollinator visitation and reproductive success of coflowering native plants. Ecol. Lett. 12, 716-728. doi: 10.1111/j.1461-0248.2009. 01319.x
Nelson, S. B., Coon, J. J., Duchardt, C. J., Fischer, J. D., Halsey, S. J., Kranz, A. J., et al. (2017). Patterns and mechanisms of invasive plant impacts on North American birds: a systematic review. Biol. Invasions 19, 1547-1563. doi: $10.1007 /$ s10530-017-1377-5

Pejchar, L. (2015). Introduced birds incompletely replace seed dispersal by a native frugivore. AoB Plants 7:plv072. doi: 10.1093/aobpla/plv072

Powers, K. D., Noble, R. E., and Chabreck, R. H. (1978). Seed distribution by waterfowl in Southwestern Louisiana. J. Wildl. Manag. 42, 598-605. doi: $10.2307 / 3800823$

Pyke, G. H., Pulliam, H. R., and Charnov, E. L. (1977). Optimal foraging: a selective review of theory and tests. Q. Rev. Biol. 52, 137-154. doi: 10.1086/409852

Pyšek, P. (1998). Alien and native species in Central European urban floras: a quantitative comparison. J. Biogeogr. 25, 155-163. doi: 10.1046/j.1365-2699.1998.251177.x

Raulings, E., Morris, K. A. Y., Thompson, R., and Nally, R. M. (2011). Do birds of a feather disperse plants together? Freshw. Biol. 56, 1390-1402. doi: 10.1111/j.1365-2427.2011.02576.x

Reynolds, C., and Cumming, G. S. (2016). Seed dispersal by waterbirds in southern Africa: comparing the roles of ectozoochory and endozoochory. Freshw. Biol. 61, 349-361. doi: 10.1111/fwb.12709

Reynolds, C., Miranda, N. A. F., and Cumming, G. S. (2015). The role of waterbirds in the dispersal of aquatic alien and invasive species. Divers. Distrib. 21, 744-754. doi: 10.1111/ddi.12334

Ricciardi, A. (2007). Are modern biological invasions an unprecedented form of global change? Conserv. Biol. 21, 329-336. doi: 10.1111/j.1523-1739.2006.00615.x

Richardson, D. M., Allsopp, N., D’Antonio, C. M., Milton, S. J., and Rejmanek, M. (2000a). Plant invasions-the role of mutualisms. Biol. Rev. Camb. Philos. Soc. $75,65-93$.

Richardson, D. M., Pyšek, P., Rejmánek, M., Barbour, M. G., Panetta, F. D., and West, C. J. (2000b). Naturalization and invasion of alien plants: concepts and definitions. Divers. Distrib. 6, 93-107. doi: 10.1046/j.1472-4642.2000.00083.x

Sanchez, M. I., Green, A. J., and Castellanos, E. M. (2006). Internal transport of seeds by migratory waders in the Odiel marshes, south-west Spain: consequences for long-distance dispersal. J. Avian Biol. 37, 201-206. doi: 10.1111/j.2006.0908-8857.03719.x

Saracco, J. F., Collazo, J. A., and Groom, M. J. (2004). How do frugivores track resources? Insights from spatial analyses of bird foraging in a tropical forest. Oecologia 139, 235-245. doi: 10.1007/s00442-004-1493-7

Schlaepfer, M. A., Sax, D. F., and Olden, J. D. (2011). The potential conservation value of non-native species. Conserv. Biol. 25, 428-437. doi: $10.1111 /$ j.1523-1739.2010.01646.x

Schlossberg, S., and King, D. I. (2010). Effects of invasive woody plants on avian nest site selection and nesting success in shrublands. Anim. Conserv. 13, 286-293. doi: 10.1111/j.1469-1795.2009.00338.x

Schor, J., Farwig, N., and Berens, D. G. (2015). Intensive land-use and high native fruit availability reduce fruit removal of the invasive Solanum mauritianum in South Africa. S. Afr. J. Bot. 96, 6-12. doi: 10.1016/j.sajb.2014.11.004

Schulze, K. A., Buchwald, R., and Heinken, T. (2014). Epizoochory via the hoovesthe European bison (Bison bonasus L.) as a dispersal agent of seeds in an open-forest-mosaic. Tuexenia 34, 131-144. doi: 10.14471/2014.34.016

Seifan, M., Hoch, E.-M., Hanoteaux, S., and Tielbörger, K. (2014). The outcome of shared pollination services is affected by the density and spatial pattern of an attractive neighbour. J. Ecol. 102, 953-962. doi: 10.1111/1365-2745.12256

Platt, S. G., Elsey, R. M., Liu, H., Rainwater, T. R., Nifong, J. C., Rosenblatt, A. E., et al. (2013). Frugivory and seed dispersal by crocodilians: an overlooked form of saurochory? J. Zool. 291, 87-99. doi: 10.1111/jzo.12052

Sorensen, A. E. (1986). Seed dispersal by adhesion. Annu. Rev. Ecol. Syst. 17, 443-463. doi: 10.1146/annurev.es.17.110186.002303

Stanley, M. C., and Lill, A. (2002). Avian fruit consumption and seed dispersal in a temperate Australian woodland. Austral. Ecol. 27, 137-148. doi: 10.1046/j.1442-9993.2002.01166.x

Strayer, D. L., D’Antonio, C. M., Essl, F., Fowler, M. S., Geist, J., Hilt, S., et al. (2017). Boom-bust dynamics in biological invasions: towards an improved application of the concept. Ecol. Lett. 20, 1337-1350. doi: 10.1111/ele.12822

Tøttrup, A. P., Chan, B. K. K., Koskinen, H., and Høeg, J. T. (2010). 'Flying barnacles': implications for the spread of non-indigenous species. Biofouling 26, 577-582. doi: 10.1080/08927014.2010.489203 
Traveset, A., Chamorro, S., Olesen, J. M., and Heleno, R. (2015). Space, time and aliens: charting the dynamic structure of Galápagos pollination networks. $A o B$ Plants 7:plv068. doi: 10.1093/aobpla/plv068

Traveset, A., Heleno, R., Chamorro, S., Vargas, P., Mcmullen, C. K., CastroUrgal, R., et al. (2013). Invaders of pollination networks in the Galápagos Islands: emergence of novel communities. Proc. R. Soc. B. 280:20123040. doi: $10.1098 / \mathrm{rspb} .2012 .3040$

Traveset, A., and Richardson, D. M. (2006). Biological invasions as disruptors of plant reproductive mutualisms. Trends Ecol. Evol. 21, 208-216. doi: 10.1016/j.tree.2006.01.006

Traveset, A., and Richardson, D. M. (2011). "Mutualisms: key drivers of invasions key casualties of invasions," in Fifty Years of Invasion Ecology: the Legacy of Charles Elton, ed D. M. Richardson (Oxford: Wiley-Blackwell), $143-160$.

Traveset, A., and Richardson, D. M. (2014). Mutualistic interactions and biological invasions. Ann. Rev. Ecol. Evol. Sys. 45, 89-113. doi: 10.1146/annurev-ecolsys-120213-091857

Van Leeuwen, C. H. A., and Van Der Velde, G. (2012). Prerequisites for flying snails: external transport potential of aquatic snails by waterbirds. Fresh. Sci. 31, 963-972. doi: 10.1899/12-023.1

Van Leeuwen, C. H. A., Van Der Velde, G., Van Groenendael, J. M., and Klaassen, M. (2012). Gut travellers: internal dispersal of aquatic organisms by waterfowl. J. Biogeogr. 39, 2031-2040. doi: 10.1111/jbi.12004

Viana, D. S., Santamaría, L., and Figuerola, J. (2016). Migratory birds as global dispersal vectors. Trends Ecol. Evol. 31, 763-775. doi: 10.1016/j.tree.2016.07.005

Vignolio, O. R., and Fernández, O. N. (2010). Cattle dung as vector of spreading seeds of exotic species in the flooding pampa grasslands (Buenos Aires, Argentina). Ann. Bot. Fenn. 47, 14-22. doi: 10.5735/085. 047.0102
Vilà, M., and D'Antonio, C. M. (1998). Fruit choice and seed dispersal of invasive vs. noninvasive Carpobrotus (Aizoaceae) in coastal California. Ecology 79, 1053-1060. doi: 10.1890/0012-9658(1998)079[1053:FCASDO]2.0.CO;2

Vilà, M., Espinar, J. L., Hejda, M., Hulme, P. E., Jarošík, V., Maron, J. L., et al. (2011). Ecological impacts of invasive alien plants: a meta-analysis of their effects on species, communities and ecosystems. Ecol. Lett. 14, 702-708. doi: 10.1111/j.1461-0248.2011.01628.x

Viviansmith, G., and Stiles, E. W. (1994). Dispersal of salt-marsh seeds on the feet and feathers of waterfowl. Wetlands 14, 316-319. doi: 10.1007/BF03160638

Westcott, D. A., and Fletcher, C. S. (2011). Biological invasions and the study of vertebrate dispersal of plants: opportunities and integration. Acta Oecol. 37, 650-656. doi: 10.1016/j.actao.2011.04.007

Will, H., Maussner, S., and Tackenberg, O. (2007). Experimental studies of diaspore attachment to animal coats: predicting epizoochorous dispersal potential. Oecologia 153, 331-339. doi: 10.1007/s00442-007-0731-1

Willson, M. F., Rice, B. L., and Westoby, M. (1990). Seed dispersal spectra: a comparison of temperate plant communities. J. Veg. Sci. 1, 547-562. doi: $10.2307 / 3235789$

Conflict of Interest Statement: The author declares that the research was conducted in the absence of any commercial or financial relationships that could be construed as a potential conflict of interest.

Copyright (C) 2018 van Leeuwen. This is an open-access article distributed under the terms of the Creative Commons Attribution License (CC BY). The use, distribution or reproduction in other forums is permitted, provided the original author(s) and the copyright owner are credited and that the original publication in this journal is cited, in accordance with accepted academic practice. No use, distribution or reproduction is permitted which does not comply with these terms. 